\title{
DIAGNÓSTICO DOS RESÍDUOS SÓLIDOS GERADOS NA ESCOLA DE ARTES, CIÊNCIAS E HUMANIDADES (EACH) COMO INSTRUMENTO PARA A ELABORAÇÃO DE UM PLANO DE GESTÃO NA UNIDADE
}

\author{
Renata Silva Araújo ${ }^{1}$, Ednilson Viana ${ }^{2}$ \\ ${ }^{1}$ Graduanda em Gestão Ambiental pela Escola de Artes, Ciências e Humanidades (EACH) da Universidade de São Paulo \\ (USP). \\ ${ }^{1}$ Pós-doutor em Saneamento pela Universidade Federal de São Carlos e professor do curso de Gestão Ambiental da \\ EACH/USP.
}

http://dx.doi.org/10.5902/223611707231

\section{RESUMO}

A Escola de Artes, Ciências e Humanidades (EACH), unidade pertencente à Universidade de São Paulo (USP) gera resíduos sólidos que podem ser classificados como perigosos e não perigosos, conforme a NBR 10.004/2004. Conhecer os tipos e quantidade de resíduos gerados, assim como as formas de manejo que os mesmos recebem é importante para a elaboração e implementação de um plano de gestão na unidade. O presente trabalho apresenta o diagnóstico de resíduos sólidos gerados na EACH no ano de 2011. Este diagnóstico refere-se aos dados de caracterização e de manejo dos resíduos ali gerados, obtidos a partir de informações cedidas pelos funcionários, observação em campo e coleta e análise dos resíduos descartados durante o período de estudo. Os resultados demonstraram que em somente uma semana foram gerados $541,93 \mathrm{Kg}$ de resíduos, sendo a maior parte classificada como rejeito. Além destes resíduos em apenas um dia foram gerados, no restaurante localizado na unidade, $233,34 \mathrm{Kg}$ de resíduos, dos quais $84,2 \%$ correspondiam à matéria orgânica. Os dados obtidos demonstram a importância de programas de coleta seletiva, compostagem de resíduos e educação ambiental para sensibilização da comunidade acadêmica. Além disso, indicam a necessidade de melhorias de infraestrutura e aquisição de equipamentos para o manejo adequado dos resíduos sólidos gerados na unidade.

Palavras-chave: Resíduos Sólidos. Diagnóstico de resíduos. Gestão de resíduos. Universidade

\section{ABSTRACT}

The School of Arts, Sciences and Humanities (EACH), unit that belongs to the University of São Paulo (USP) generates a large amount of solid waste that can be classified as hazardous and non-hazardous, according to NBR 10.004/2004. Knowing the types and quantity of waste generated, as well as forms of handling is important to get elaboration and implementation of a management plan for the unit. This paper presents a diagnosis of solid waste generated in EACH year 2011. This diagnosis refers to data characterization and of handling of waste generated there, obtained from information ceded by employees, field observation and collection and analysis of waste discarded during the study period. Results showed that in only one week was generated $541.93 \mathrm{~kg}$ of waste, most of which is classified as refuse. In addition were generated only one day, 
Rev. Elet. em Gestão, Educação e Tecnologia Ambiental (e-ISSN: 2236-1170)

in the restaurant located in the unit, $233.34 \mathrm{~kg}$ of waste, with $84.2 \%$ corresponded to organic matter. The data demonstrate the importance of programs of selective collection, composting and environmental education to sensitization of the academic community. Also, indicate the need for infrastructure improvements and acquisition of equipment for the proper handling of solid waste generated in the unit.

Keywords: Solid Waste. Diagnosis of waste. Management of waste. University.

\section{INTRODUÇÃO}

Segundo Corrêa et al. (2010) a geração de resíduos numa instituição de ensino superior (IES) é heterogênea, devido à complexidade e às particularidades das diversas atividades existentes neste local, tornando o processo de gestão desses resíduos um desafio. Martins e Silveira (2010) também citam a diversidade de resíduos gerados nas IESs afirmando que muitas instituições possuem características semelhantes às de cidades industriais, por gerarem resíduos de diferentes tipos e decorrentes de diferentes atividades e setores.

Dias et al. (2010) ao tratarem do caso de gestão de resíduos sólidos na universidade estadual de Feira de Santana, na Bahia, comentam sobre a diversidade de resíduos, que são gerados nas universidades, que somadas ao desconhecimento, à falta de infraestrutura para o gerenciamento e de legislações, faz com que, muitas vezes, o descarte dos resíduos seja relegado a um segundo plano. Assim, Cruz et al. (2009) afirmam que no meio acadêmico o gerenciamento dos resíduos sólidos ainda é incipiente, sendo estes, na sua maioria, descartados de forma inadequada.

No entanto, cabe dizer que muitas universidades vêm buscando equacionar os seus problemas com relação ao gerenciamento dos resíduos sólidos. Para tanto diversas iniciativas tem sido adotadas, dentre elas pode-se citar (1) educação ambiental para a comunidade acadêmica, (2) implementação de coleta seletiva e sistema de compostagem; (3) constituição e instalação de comissões para tratar de assuntos relacionados aos resíduos; e (4) implementação de sistema de gestão ambiental (SGA).

Tais iniciativas são de extrema relevância para garantir o manejo adequado dos resíduos e devem ser realizadas em conjunto e juntamente com outras ações que sejam relevantes para atender as características e particularidades de cada instituição de ensino. Conto (2010) afirma que os problemas relacionados aos resíduos em universidades são complexos, exigindo soluções complexas e sistêmicas, mas principalmente voltadas à prevenção, ou seja, redução da geração de resíduos. Porém, esta autora chama a atenção para o fato de que a prevenção dos resíduos ainda é muitas vezes negligenciada nas universidades, mas que ao mesmo tempo se apresenta como uma das ações mais importante para reduzir os impactos ambientais causados pelos resíduos.

$\mathrm{Na}$ Escola de Artes, Ciências e Humanidades (EACH), unidade pertencente à Universidade de São Paulo (USP) a problemática relacionada aos resíduos sólidos também é complexa. A quantidade de freqüentadores desta unidade, assim como as diversas atividades de ensino, pesquisa e extensão que ocorrem na mesma contribuem para a produção de uma quantia significativa e diversificada de resíduos sólidos que podem ser classificados como perigosos e não- 
perigosos conforme a NBR 10004/2004, exigindo, portanto, um planejamento que garanta um manejo adequado destes resíduos, de acordo com as suas características.

A elaboração e adoção de um plano de manejo que abarque os diversos tipos de resíduos gerados na unidade, além de prevenir e minimizar os problemas relacionados à poluição ambiental, exposição dos usuários da unidade à riscos de contaminação e acidentes, pode gerar ainda outros benefícios relacionados a formação mais consciente dos discentes, a diminuição do desperdício e economia de recursos financeiros e materiais.

Para a elaboração de um plano de manejo dos resíduos sólidos em instituições de ensino é necessário que se conheça o tipo e quantidade de resíduos ali gerados, bem como as formas de manejo que os mesmos recebem. Este conjunto de dados compõe o diagnóstico dos resíduos, que oferece informações imprescindíveis para compreensão da realidade local sobre a gestão dos resíduos, permitindo, tomar decisões que busquem adequar o manejo dos resíduos sólidos, assim como busque reduzir a sua produção.

Faz necessário esclarecer, que neste trabalho será utilizada a definição de manejo e gerenciamento de resíduos apresentada por Tenório e Espinosa (2004), que afirmam que

“manejo é o conjunto de atividades envolvidas com os resíduos sólidos, sob o aspecto operacional, envolvendo sua coleta, transporte, acondicionamento, tratamento e disposição final. Já o gerenciamento abrange o manejo e também todos os aspectos relacionados ao planejamento, à fiscalização e à regulamentação".

Diante da necessidade de se conhecer as formas de manejo, além do tipo e quantidade dos resíduos sólidos gerados na EACH para a elaboração de um plano de gestão adequado, propõe-se este trabalho, onde são apresentados dados qualitativos e quantitativos sobre os resíduos produzidos na unidade.

\section{METODOLOGIA}

Inaugurada em 2005, a Escola de Artes, Ciências e Humanidades (EACH), ou como também é conhecida USP Leste, está localizada na zona leste da cidade de São Paulo e é uma das unidades pertencentes à Universidade de São Paulo (USP).

Embora esta unidade seja relativamente recente, ela possui uma infraestrutura composta por salas de aula e de docentes, laboratórios didáticos e de pesquisa, restaurante universitário, ambulatório, departamentos administrativos e ginásio poliesportivo ${ }^{3}$. Atualmente, esta unidade

\footnotetext{
3 O mapa da unidade, contendo todos os setores existentes, assim como os futuros, pode ser visualizado no site da EACH: http://each.uspnet.usp.br/site/mapa.php
} 
conta com o oferecimento de dez cursos de graduação e cinco de pós-graduação ${ }^{4}$, além de algumas atividades e eventos voltados para a comunidade em geral.

Assim, em 2011, freqüentavam a unidade, cerca de 4.565 alunos, 255 docentes e 403 funcionários, dos quais apenas 75 eram responsáveis pela limpeza da unidade.

O diagnóstico dos resíduos sólidos da EACH foi realizado ao longo do ano de 2011 e envolveu a coleta de dados operacionais e de caracterização dos resíduos sólidos ali gerados.

Os dados operacionais referiram-se aos dados sobre o manejo dos resíduos desde a etapa de geração até o seu destino final e foram obtidos por meio de informações cedidas pelos funcionários da unidade e observação local. A caracterização gravimétrica foi realizada através da pesagem dos resíduos sólidos gerados nos vários setores desta unidade.

Devido à grande quantidade de prédios e setores que compõe a unidade, foi necessário fazer um planejamento e distribuição das atividades ao longo dos 12 meses de duração do diagnóstico. Assim, as informações sobre composição gravimétrica, acondicionamento e armazenamento dos resíduos sólidos foram coletadas em semanas diferentes, facilitando a obtenção e análise dos dados.

Para a caracterização, os resíduos gerados em cada setor e prédio foram coletados ao longo de uma semana, sendo estudados e pesados todos os dias. Para que a caracterização dos resíduos correspondesse ao descarte de materiais de uma semana, a coleta dos dados iniciava-se sempre na sexta feira à tarde, permitindo que os resíduos sólidos gerados nos finais de semana também fossem armazenados. O armazenamento, estudo e pesagem destes materiais tinham continuidade nos outros dias da semana, finalizando a coleta de dados na sexta feira da semana seguinte. Deste modo, para que todos os centros geradores de resíduos da unidade fossem caracterizados, foram necessários três meses.

Para a coleta dos resíduos durante a etapa de caracterização utilizou-se um coletor de 1.000 litros, onde eram depositados os resíduos sólidos pelos funcionários responsáveis pela limpeza. Este coletor foi identificado por meio de rótulos específicos, que indicavam a origem dos resíduos a serem depositados e chamavam a atenção para a necessidade de não se retirar nenhum material do recipiente. A presença destes rótulos também facilitava a visualização do mesmo por parte dos funcionários e tinha como finalidade evitar possíveis misturas com resíduos de outros prédios. Além disso, um diálogo com os funcionários responsáveis pela limpeza da unidade foi realizado antes e durante a coleta de dados, com o objetivo de orientá-los e garantir a qualidade da separação e armazenamento dos resíduos.

Os resíduos armazenados no coletor eram recolhidos, separados por tipo e depois pesados, com o auxílio de uma balança digital com capacidade para pesar até 50Kg. A tipologia estabelecida nesta caracterização foi: rejeitos, papel, metal, plástico, vidro e outros. Os resíduos oriundos dos banheiros, por apresentarem periculosidade, foram apenas pesados e classificados como rejeitos.

\footnotetext{
${ }^{4}$ No ano de 2011, ano que foi realizado esta pesquisa, havia cinco cursos de pós-graduação. No entanto, já está previsto para o ano de 2013 um novo curso de pós-graduação na unidade, totalizando seis cursos de pós-graduação.
} 
Os resíduos provenientes do ambulatório também não foram separados, devido a sua composição e periculosidade, sendo apenas pesados e classificados como rejeitos.

Os resíduos produzidos no restaurante universitário foram coletados de forma diferenciada. Esta coleta foi realizada em apenas um dia, na terça feira, durante o almoço e o jantar. Os resíduos produzidos, no período de coleta, foram separados por tipo, pesados e depois descartados. Já os restos alimentares foram pesados e, posteriormente, tiveram uma amostra coletada para análise do teor de umidade e $\mathrm{pH}$.

Para verificar as condições de acondicionamento, armazenamento, bem como identificar falhas de manejo e medidas já adotadas para diminuir a quantidade de resíduos enviados para aterros sanitários, visitas in loco foram realizadas por toda a unidade. Além disso, através dos funcionários que trabalham no local foi possível obter informações adicionais que contribuíram para a compreensão da problemática de produção e manejo de resíduos neste local.

Por fim, deve-se dizer que os resíduos de equipamentos eletrônicos, que são enviados para o centro de descarte e reuso de resíduos de informática (CEDIR) da USP, assim como os resíduos de poda e capinagem, construção civil, lâmpadas e resíduos laboratoriais perigosos, que também são gerados na unidade, não serão abordados neste trabalho.

\section{RESULTADOS E DISCUSSÃO}

A partir da coleta de dados foi possível verificar que em apenas uma semana foram descartados e enviados para o aterro sanitário 541,93 $\mathrm{Kg}$ de resíduos sólidos, sendo 33,43 $\mathrm{Kg}$ de papel; 7,58 Kg de metal; $131,57 \mathrm{Kg}$ de rejeitos; $13,68 \mathrm{Kg}$ de plástico; $1,42 \mathrm{Kg}$ de vidro; 348, $52 \mathrm{Kg}$ de rejeitos oriundos dos banheiros; $3,04 \mathrm{Kg}$ de rejeitos provenientes do ambulatório e 2,69 $\mathrm{Kg}$ classificado como outros, no qual estão inseridos tecidos, borracha e uma pequena quantidade de equipamentos eletrônicos.

Assim, observa-se que os materiais descartados em maior quantidade referem-se a rejeitos, oriundos dos banheiros, do ambulatório e de outros setores da unidade (Figura 1), totalizando $89,71 \%$ dos resíduos gerados em somente uma semana. 
Rev. Elet. em Gestão, Educação e Tecnologia Ambiental (e-ISSN: 2236-1170)

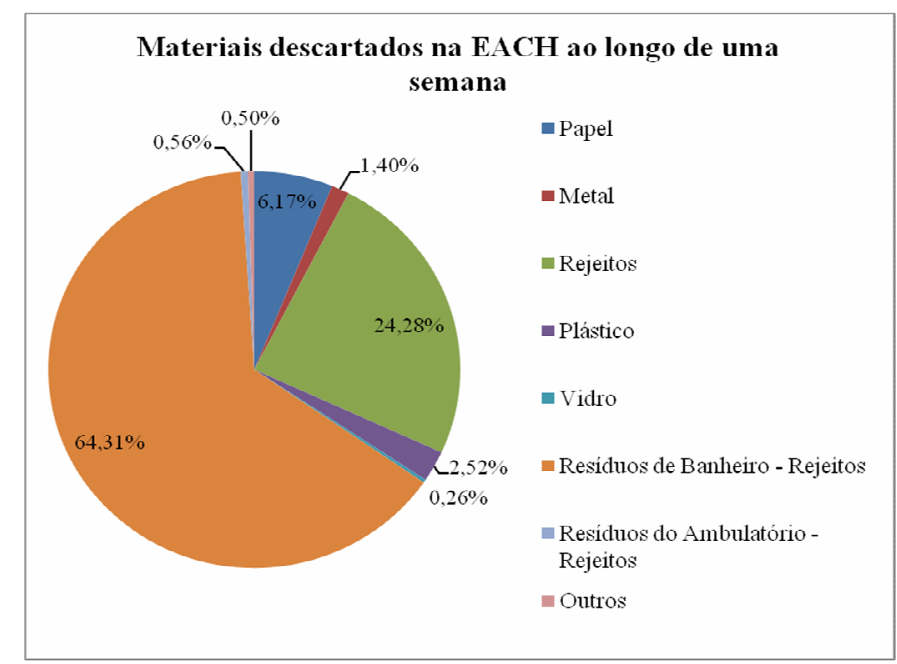

Figura1: Resíduos sólidos descartados na EACH ao longo de uma semana no ano de 2011.

Além destes resíduos gerados ao longo de uma semana, a coleta de dados permitiu identificar que em um dia foram gerados $233,34 \mathrm{Kg}$ de resíduos sólidos no restaurante universitário. Deste total, 84,2\%, ou seja, $208 \mathrm{Kg}$ referem-se à matéria orgânica, incluindo sobras de alimento descartadas pelos usuários, saladas preparadas e não consumidas, e folhas de vegetais não utilizadas pelo restaurante.

Além destes restos alimentares descritos acima, o restaurante ainda descarta mais alimentos armazenados em cubas, ou seja, em recipientes com volumes de $15 \mathrm{~cm}^{3}, 22,5 \mathrm{~cm}^{3}$ e 30 $\mathrm{cm}^{3}$ para recipientes pequenos, médios e grandes, respectivamente. Os alimentos presentes nestes recipientes eram diretamente encaminhados para a empresa terceirizada que fornecia estes alimentos e, posteriormente, descartados. Assim, infere-se que a quantidade de resíduos alimentares que foi descartada ultrapassava a quantia verificada ao longo deste levantamento de dados.

Também foram descartados no restaurante universitário $21,48 \mathrm{Kg}$ de rejeitos, 0,58 $\mathrm{Kg}$ de papel, 0,20 $\mathrm{Kg}$ de pratos de cerâmica e $3 \mathrm{Kg}$ de metal, sendo que somente o metal fora enviado para a reciclagem, enquanto os demais foram encaminhados para uma empresa terceirizada, responsável pela destinação final dos resíduos gerados no restaurante.

Nota-se que a geração de resíduos classificados como matéria orgânica é bastante significativa considerando os resultados obtidos em somente um dia de coleta, onde foram atendidos 1.576 usuários.

É relevante destacar que dos 208 kg de matéria orgânica descartada, cerca de 56\% eram decorrentes das sobras de alimentos descartadas pelos próprios usuários do restaurante, evidenciando que o desperdício de alimentos decorria não somente da empresa que fornecia os alimentos, mas também das pessoas que usavam os serviços do restaurante.

A análise de amostras coletadas destas sobras alimentares mostrou que estas possuíam, em média, 74,62\% de umidade e $\mathrm{pH}$ de 5,97. Assim, verifica-se que estes restos alimentares possuíam uma potencialidade para serem compostados, se fossem adotadas medidas para 0 controle da umidade e pH. Além disso, demonstra o quanto se perde de matéria-prima que poderia gerar adubo para a vegetação da própria unidade. 
É importante citar que ao longo da pesquisa foi possível verificar que os resíduos gerados no restaurante universitário eram manejados de forma diferente dos demais resíduos que eram gerados na unidade. Isto porque o manejo destes resíduos era de responsabilidade de uma empresa terceirizada, que fornece os alimentos para os usuários do restaurante.

Assim, os resíduos gerados e descartados no próprio restaurante eram transportados com o auxílio de um carrinho próprio até uma lixeira localizada nos fundos do restaurante, onde os resíduos eram armazenados temporariamente, sendo coletados três vezes por semana por uma empresa particular, que se responsabilizava pela destinação final.

A geração de rejeitos também se destaca na unidade. Como demonstrado anteriormente, a maior parte dos resíduos gerados correspondia a rejeitos, sendo a maior parte destes oriundos dos banheiros, seguidos pelos oriundos de outros setores da unidade e, posteriormente pelos oriundos dos ambulatórios.

Deve-se dizer que os rejeitos, que representam $24,28 \%$ dos materiais descartados, continham uma parcela de matéria orgânica, que era gerada nos diversos setores da unidade, tais como setores administrativos, salas de aula e de docentes, salas dos funcionários, e outros. Esta matéria orgânica correspondia à restos alimentares, cascas de frutas e pó de café. Assim, ao invés de serem enviados para o aterro sanitário, estes materiais poderiam ser utilizados em sistemas de compostagem.

É necessário chamar a atenção para os resíduos do ambulatório, que embora representem somente $0,56 \%$ dos resíduos gerados em uma semana, são considerados resíduos perigosos, por apresentarem características de patogenicidade.

Observou-se que no ambulatório, que faz atendimentos de casos simples relacionados à saúde, não havia um sistema de separação e coleta dos resíduos perigosos, exceto para os perfurocortantes. Deste modo, os resíduos perfurocortantes, que eram gerados em pequena quantidade, eram armazenados em caixas descarpack, enquanto os demais eram acondicionados juntamente com os resíduos não perigosos.

As principais falhas de manejo identificadas neste local foram a falta de sacos brancos e coletores adequados para o acondicionamento e armazenamento temporário dos resíduos em conformidade com a RDC 306/2004.

No que diz respeito à produção e descarte de materiais recicláveis secos, descritos anteriormente, deve-se dizer que o papel foi gerado em maior quantidade, representando 56,85\% destes materiais, seguido do plástico, com 23,27\% e metal, com 12,89\% (Figura 2). Um programa abrangente de coleta seletiva na unidade, que envolvesse a separação e coleta de diversos materiais, poderia permitir o reaproveitamento de todos estes resíduos recicláveis, reduzindo ainda mais a quantidade de resíduos encaminhados para a coleta comum. 


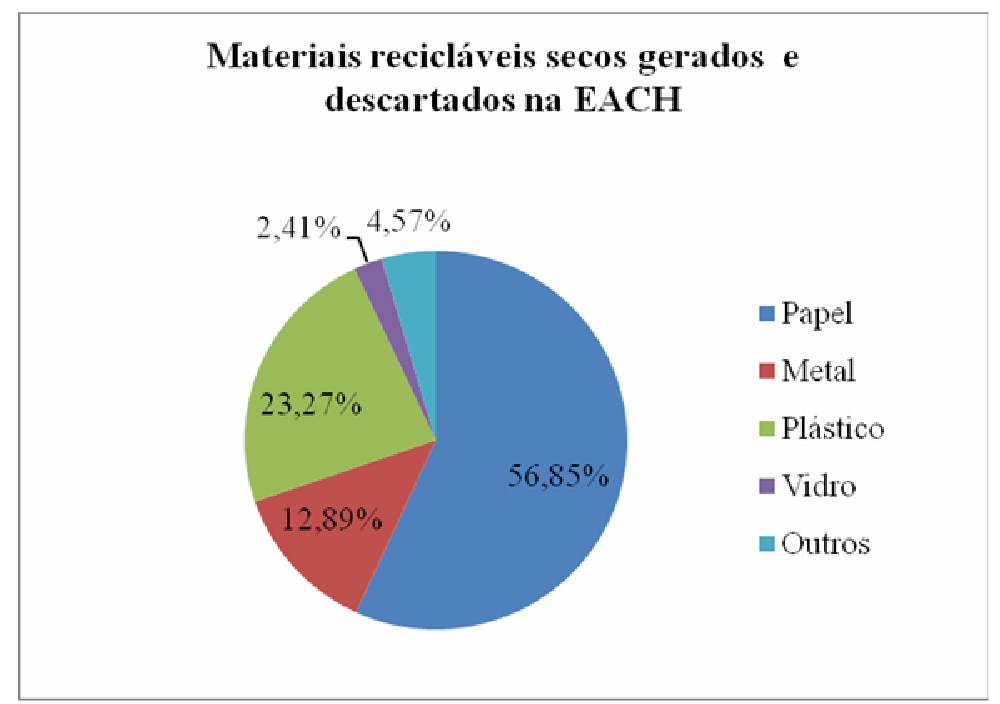

Figura 2: Composição gravimétrica dos materiais recicláveis secos gerados e descartados no lixo comum, ao longo de uma semana.

É importante dizer, que a unidade possui um sistema de separação e coleta de papel, que embora incipiente, incentivava os diversos setores da unidade a separar este material.

Assim, acredita-se que o descarte de papel no lixo comum poderia ser ainda maior, se não houvesse a iniciativa de separação, coleta e reciclagem do mesmo. No entanto, nota-se a necessidade de tornar este sistema de coleta de papéis mais eficiente, investindo em infraestrutura apropriada, bem como investindo em programas de comunicação, para difusão de informações e programas de educação ambiental, para sensibilização dos usuários da unidade, onde estão incluídos não apenas os alunos, mas também os docentes, funcionários e prestadores de serviço.

A necessidade de sensibilização com a questão dos resíduos sólidos na EACH é evidenciada pelo resultado obtido a partir da coleta de dados por setor, onde foi possível identificar que a maior parte do descarte de papel no lixo comum ocorria nas salas dos docentes, departamentos administrativos e serviço de fotocópia, respectivamente.

A produção de plástico também se mostrou significativa, sobretudo se for considerada a leveza deste material. Constatou-se que a produção deste material ocorria em maior quantidade nos departamentos administrativos e nas salas dos docentes, com o descarte de copos descartáveis, feito de poliestireno (PS). Enquanto que nas salas de aula e nas proximidades da lanchonete, onde também havia uma produção significativa de resíduos de plástico, notou-se que havia um descarte maior de embalagens de polipropileno (PP) e polietileno tereftalato (PET).

Os dados obtidos sobre o descarte de metais foram bastante surpreendentes. Durante a coleta e análise dos materiais identificou-se uma pequena quantidade de latas de aço e latinhas de alumínio descartadas no lixo comum. Houve apenas um dia em que a quantidade deste material registrou 5,09 $\mathrm{Kg}$, sendo decorrente do descarte de placas de metal, oriundas do serviço de transporte, localizado na unidade. 
Rev. Elet. em Gestão, Educação e Tecnologia Ambiental (e-ISSN: 2236-1170)

Observou-se que o descarte de materiais de aço não é algo comum na unidade, e que as latinhas de alumínio eram recolhidas dos coletores por alguns funcionários. Além disso, a cantina existente na unidade disponibilizava um coletor exclusivamente para a coleta de latinhas, sendo que as mesmas não eram descartadas no lixo comum.

Embora estas ações contribuíssem para a diminuição da quantidade de materiais do tipo metal no lixo comum, elas também demonstram a necessidade de uma ação mais efetiva desta instituição de ensino, que a partir da elaboração e aplicação de um plano de gestão de resíduos deveria garantir a separação e encaminhamento deste material para o reaproveitamento.

Dos materiais analisados, também foi possível identificar uma pequena quantidade de retalhos de tecidos; borracha, na forma de solado de tênis; e alguns equipamentos eletrônicos. Chama-se a atenção para os equipamentos eletrônicos, que embora tenham sido identificados em pequena quantidade, poderiam ter recebido outra destinação.

A Universidade de São Paulo (USP) possui um centro de descarte e reuso de resíduos de informática (CEDIR), que também recolhe os resíduos eletrônicos da $E A C H$, contribuindo para que os equipamentos eletrônicos não recebam uma destinação final inadequada. Assim, se não houvesse um plano de recolhimento destes materiais, acredita-se que a quantidade de equipamentos eletrônicos descartados de forma inadequada seria maior.

Entretanto, deve-se considerar a relevância da unidade e dos prestadores de serviço, localizados neste campus, em estabelecerem acordos com os fabricantes de equipamentos eletrônicos, para que estes recolham esses materiais, responsabilizando-se pela destinação correta dos resíduos eletrônicos.

É necessário ressaltar que, de acordo com a Política Nacional de Resíduos Sólidos (PNRS), instituída pela lei no $12.305 / 10$, os fabricantes, importadores, distribuidores e comerciantes de produtos eletroeletrônicos e seus componentes são obrigados a estruturar e implementar sistemas de logística reversa (BRASIL, 2010).

Assim, o estabelecimento de acordos por parte da direção da unidade e seus prestadores de serviço, juntamente com os fabricantes e demais envolvidos na comercialização dos produtos eletrônicos possui embasamento na lei, que sendo cumprida auxiliaria o manejo correto dos resíduos eletrônicos, evitando que os mesmos fossem destinados para o lixo comum.

Com relação ao descarte do vidro nos diferentes setores da unidade, verificou-se que seu descarte é relativamente pequeno, tendo totalizando somente 1,42 $\mathrm{Kg}$ em uma semana.

Nos laboratórios didáticos e de pesquisa, também eram gerados resíduos não perigosos em pequena quantidade sendo os principais: vidro não contaminado, matéria orgânica, papéis e plásticos, sendo que os vidros eram separados e armazenados para reaproveitamento no próprio laboratório.

No que diz respeito ao acondicionamento dos resíduos sólidos, observou-se que os mesmos são acondicionados em sacos de lixo, na cor preta, com volumes variados dependendo do tamanho do coletor e do setor em que o mesmo estava localizado. Foi possível constatar também, que estes recipientes destinados ao acondicionamento dos resíduos não eram resistentes. Deste 
modo, foi possível observar, durante a coleta de dados, que alguns sacos de lixo encontravam-se rasgados, dificultando o transporte e o armazenamento temporário e seguro dos mesmos.

Durante a realização de visitas in loco, constatou-se também a necessidade de equipar alguns setores com coletores com volume maior e com tampa de vedação para garantir o armazenamento adequado dos resíduos sólidos. Constatou-se ainda que alguns recipientes destinados ao armazenamento temporário dos resíduos, os containeres de 1.000 litros, estavam quebrados, facilitando o acesso de roedores e insetos aos resíduos.

O armazenamento dos materiais recicláveis também se mostrou inadequado devido ao fato dos containeres de 1.000 litros serem, aparentemente, insuficientes para armazenar temporariamente estes materiais. Assim, observava-se que os materiais destinados a reciclagem ficavam expostos ao sol e a chuva (Figura 3 ).

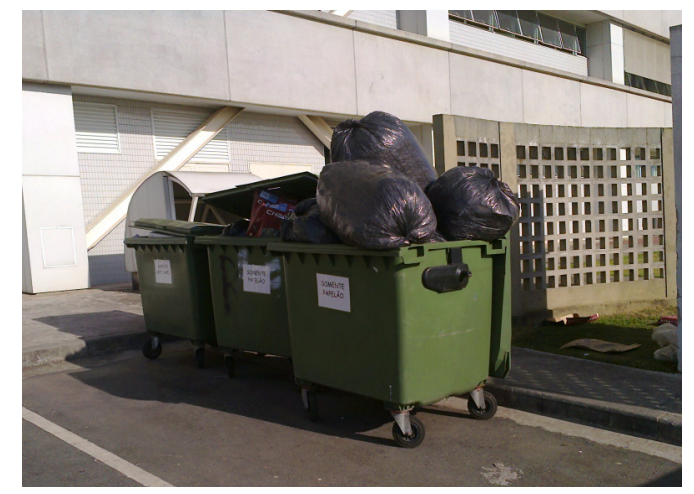

Figura 3: Containeres destinados ao armazenamento temporário dos materiais recicláveis secos na $\mathrm{EACH}$.

Deve-se dizer que estes coletores não armazenavam somente papéis, material que a unidade incentivava separar, mas também plásticos e metais, que eram colocados nestes locais pelos funcionários dos diversos setores, aumentando a quantidade de material destinado à reciclagem. É importante citar que ao longo da realização deste trabalho identificou-se que, frequentemente, havia diversos tipos de materiais misturados com os materiais recicláveis, prejudicando o trabalho de separação de parte dos recicláveis.

Com relação ao transporte dos resíduos, identificou-se que os mesmos eram transportados de forma manual pelos funcionários responsáveis pelo serviço de limpeza ou com o auxílio de um carrinho, que não era destinado exclusivamente para o transporte dos resíduos. Assim, foi possível identificar que a falta de um número maior de carrinhos adequados e destinados ao transporte exclusivo dos resíduos, dificultava o transporte destes materiais, bem como gerava riscos de contaminação e desconforto aos funcionários.

Os resíduos abordados neste trabalho, exceto os gerados no restaurante universitário eram armazenados em coletores de 1000 litros, e posteriormente encaminhados para uma lixeira, que ficava na parte externa da unidade, onde os resíduos eram recolhidos três vezes na semana pela própria prefeitura de São Paulo. No mesmo ano esta coleta passou a ser terceirizada, pois segundo 
a lei municipal $n=13.478 / 02$, os grandes geradores de resíduos, que produzem mais de 200 litros destes materiais por dia, são responsáveis pela coleta, transporte, tratamento e destinação final dos resíduos sólidos.

Além disso, os resíduos passaram a ser armazenados dentro do perímetro da unidade, uma vez que, de acordo com esta mesma lei, é vedada aos grandes geradores de resíduos a disposição dos mesmos em áreas públicas, incluindo passeios e sistema viário, sob pena de multa (PREFEITURA DE SÃO PAULO, 2002).

\section{CONSIDERAÇÕES FINAIS}

Os dados descritos neste trabalho referem-se ao ano de 2011 e, portanto, representam a realidade daquele ano. No entanto, os dados apresentados fornecem informações relevantes sobre o tipo e quantidade de resíduos gerados e formas de manejo, contribuindo com a elaboração de um plano de gestão para estes materiais.

Os dados obtidos revelaram ainda a existência de algumas etapas que necessitam ser cumpridas para garantir o manejo adequado e redução da produção de resíduos, além de assegurar a segurança dos usuários da unidade, inclusive dos funcionários responsáveis pelo serviço de limpeza.

Nota-se a necessidade de um plano de gestão que busque incentivar a redução da produção de resíduos e estabeleça programas e ações voltados à coleta seletiva dos diversos materiais recicláveis gerados, assim como a compostagem da matéria orgânica produzida.

É importante destacar que a aplicação de um plano de gestão destes resíduos, que englobe ações de redução, reutilização e reciclagem, só irá obter êxito com o apoio da comunidade universitária. Deste modo, nota-se a relevância de ações voltadas à educação ambiental como instrumento de sensibilização, que impulsiona a mudança de hábitos dos docentes, alunos, funcionários e prestadores de serviço, sendo capaz de contribuir com o sucesso do plano de gestão de resíduos do campus.

Além do comportamento dos usuários da unidade, é de extrema importância que a EACH adquira uma estrutura adequada para armazenar os resíduos recicláveis e não recicláveis, facilitando o manejo correto dos mesmos.

Conto (2010) afirma que a falta de planejamento para o armazenamento de resíduos nos diferentes setores é ainda uma lacuna em muitas universidades. No entanto, equacionar os problemas de estrutura para o armazenamento dos diferentes tipos de resíduos gerados nas universidades é fundamental para diminuir os problemas relacionados à poluição, exposição dos resíduos aos usuários e proliferação de insetos e roedores. 
Também é importante ressaltar a relevância de equipamentos, como carrinhos para transporte de resíduos e recipientes adequados e resistentes para o acondicionamento e armazenamento dos resíduos, para garantir o manejo seguro dos materiais descartados.

Por fim, é necessário ressaltar que as boas práticas de manejo dos resíduos sólidos podem resultar em inúmeros benefícios tanto para a comunidade universitária, quanto para a sociedade, uma vez que estas práticas podem contribuir com a minimização de impactos ambientais e redução de gastos com transporte, armazenamento e destinação final dos resíduos, entre outros.

\section{AGRADECIMENTOS}

Aos funcionários da $\mathrm{EACH}$ e do serviço de segurança, que cederam informações importantes para este estudo;

A toda equipe do departamento de Infraestrutura da unidade, que disponibilizou informações, cedeu equipamentos para a coleta dos materiais e autorizou os funcionários do serviço de limpeza a contribuírem com a pesquisa;

Aos funcionários do serviço de limpeza, sem os quais este trabalho não obteria êxito;

Aos técnicos dos laboratórios de pesquisa e didático, pela atenção, dedicação e apoio ao trabalho;

Aos funcionários do COSEAS (Coordenadoria de Assistência Social) da EACH pela autorização para coleta de dados e informação referentes ao Restaurante Universitário;

Aos funcionários do Restaurante Universitário pela ajuda e paciência durante a coleta de dados no local; pesquisa;

Aos docentes e discentes que contribuíram com sugestões, informações e apoio à

E a todos os demais envolvidos neste trabalho, que direta ou indiretamente contribuíram com a pesquisa.

\section{REFERÊNCIAS}

ABNT. ASSOCIAÇÃO BRASILEIRA DE NORMAS TÉCNICAS. NBR 10004: resíduos sólidos - classificação. Rio de Janeiro: ABNT, 2004.

ANVISA. AGÊNCIA NACIONAL DE VIGILÂNCIA SANITÁRIA. RDC 306, de 10 de dezembro de 2004. Dispõe sobre o regulamento técnico para o gerenciamento de resíduos de serviços de saúde. Disponível em: < http://bvsms.saude.gov.br/bvs/saudelegis/anvisa/2004/res0306_07_12_2004.html >. Acesso em: 05.04.2012. 
Rev. Elet. em Gestão, Educação e Tecnologia Ambiental (e-ISSN: 2236-1170)

BRASIL. Lei no 12.305, de 2 de agosto de 2010. Institui a Política Nacional de Resíduos sólidos; altera a lei no 9.605, de 12 de fevereiro de 1998; e dá outras providências. Disponível em: < http://www.planalto.gov.br/ccivil_03/_ato2007-2010/2010/lei/l12305.htm >. Acesso em: 08.11.2012.

CONTO, S. M. de. Gestão de resíduos em universidades: uma complexa relação que se estabelece entre heterogeneidade de resíduos, gestão acadêmica e mudanças comportamentais. In: CONTO, S. M. de (org.). Gestão de resíduos em universidades. Caxias do Sul: Educs, 2010.

CORRÊA, L. B.; MENDES, P. M.; CORRÊA, É. K. A gestão dos resíduos sólidos na UFPel: construção de políticas integradas na perspectiva da educação ambiental. In: CONTO, S. M. de (org.). Gestão de resíduos em universidades. Caxias do Sul: Educs, 2010.

CRUZ, J. A. dos R.; CARVALHO, E. H. de; PFEIFFER, S. C.. Diagnóstico dos resíduos sólidos da universidade federal de Goiás. In: CONGRESSO BRASILEIRO DE ENGENHARIA SANITÁRIA E AMBIENTAL, 25., 2009, Recife. ABES - Associação Brasileira de Engenharia Sanitária e Ambiental. Disponível em: < http://paginas.ufrgs.br/sga/SGA/material-de-apoio/textos/textos-apoio/links/III-244.pdf >. Acesso em: 30.03.2011.

DIAS, S. M. F.; VAZ, L. M. S.; CAMPOS, A. C. A. Gestão de resíduos sólidos para sociedades sustentáveis (GRSSS) na Universidade Estadual de Feira de Santana (BA): história, desafios e perspectivas. In: CONTO, S. M. de (org.). Gestão de resíduos em universidades. Caxias do Sul: Educs, 2010.

EACH. Escola de Artes, Ciências e Humanidades. Disponível em: < http://each.uspnet.usp.br/ >. Acesso em: 06.04.2011.

MARTINS, A. F.; SILVEIRA, D. D.. Gestão de resíduos em universidades: a experiência da Universidade Federal de Santa Maria. In: CONTO, S. M. de (org.). Gestão de resíduos em universidades. Caxias do Sul: Educs, 2010.

PREFEITURA DE SÃO PAULO. Lei no 13.478, de dezembro de 2002. Dispõe sobre a organização do Sistema de Limpeza Urbana do Município de São Paulo; cria e estrutura seu órgão regulador; autoriza o Poder Público a delegar a execução dos serviços públicos mediante concessão ou permissão; institui a Taxa de Resíduos Sólidos Domiciliares - TRSD, a Taxa de Resíduos Sólidos de Serviços de Saúde - TRSS e a Taxa de Fiscalização dos Serviços de Limpeza Urbana - FISLURB; cria o Fundo Municipal de Limpeza Urbana - FMLU, e dá outras providências. Disponível em: < http://www3.prefeitura.sp.gov.br/cadlem/secretarias/negocios_juridicos/cadlem/integra.asp?alt=3112200 2L\%20134780000 >. Acesso em: 08.11.2012.

TENÓRIO, J. A. S.; ESPINOSA, D. C. R.. Controle Ambiental de Resíduos. In: PHILIPPI JUNIOR, A.; ROMÉRO, M. de A.; BRUNA, G. C.. (Orgs.). Curso de Gestão Ambiental. Barueri: Manole, 2004. 